\title{
Storage of non-dormant hardwood seeds: new trends
}

\author{
C. Muller ${ }^{1}$ and M. Bonnet-Masimbert ${ }^{2}$ \\ 1 INRA-CRF, Laboratoire de Graines, Forêt d'Amance Champenoux, BP 35, 54280 Seichamps, and \\ 2INRA, Station d'Amélioration des Arbres Forestiers, Ardon 45160 Olivet, France
}

\section{Introduction}

More than $60 \%$ of forestry seeds, especially hardwood species, are in a more or less deep dormancy state. As a consequence of its important genetic variability, this dormancy is very heterogeneous: it can vary from year to year, from seed lot to seed lot and between seeds within a seed lot. Generally, it is a type of physiological dormancy caused by a germination-inhibiting mechanism in the embryo which often requires a long prechilling period (1-8 months) to eliminate it. Sometimes, this physiological dormancy can be associated with a physical impermeability of the seed coat to water or with a morphological underdevelopment of the embryo. Nurserymen are generally unaware of the dormancy requirements of their seeds, which has resulted in an enormous waste of seeds and mediocre yields in the nurseries.

\section{Materials and Methods}

The classical method of breaking the dormancy, stratification (i.e., pretreatment on a wet me- dium at $3-4^{\circ} \mathrm{C}$ ), is limited in dealing with the heterogeneity within a seed lot.

A new and original methodology has been developed on the basis of Polish research work applied to beechnuts (Suszka, 1975). It eliminates the dormancy before storage, allowing a continuous supply of non-dormant seeds ready to germinate. Dormancy is eliminated by pretreatment without medium. Seeds are hydrated, maintained at a controlled level of moisture content (permitting the removal of dormancy without allowing germination) and finally dehydrated to below $10 \%$ moisture content ( $\%$ MC) before storage. This method allows a fast and uniform germination in the laboratory as well as in the nursery.

We have developed this methodology further in our laboratory and report here the results obtained with: Fagus silvatica, Fraxinus excelsior and Prunus avium.

\section{Results}

\section{Fagus silvatica}

Beechnuts are typical examples of seeds with a variable but often very deep dormancy. Long-term storage of the seeds is now possible. However, due to dormancy problems, nurserymen still have some difficulty producing the desired number of seedlings even from high quality seed lots. 
Table I. Nursery seedling emergence of beechnuts after 30 mo of dry storage.

\begin{tabular}{|c|c|c|c|}
\hline \multirow[t]{3}{*}{ Lot } & \multicolumn{3}{|c|}{ Pretreatment at $3^{\circ} \mathrm{C}$} \\
\hline & \multicolumn{2}{|c|}{ without medium (10 wk) } & \multirow{2}{*}{$\begin{array}{l}\text { stratification } \\
\text { after storage }\end{array}$} \\
\hline & before storage & after storage & \\
\hline A & 58.6 & 53.0 & 48.0 \\
\hline B & 62.7 & 62.0 & 42.0 \\
\hline C & 76.0 & 55.4 & 47.4 \\
\hline Mean & $65.8^{\mathrm{a}^{*}}$ & $56.8^{b^{*}}$ & $45.8^{\mathrm{C} *}$ \\
\hline
\end{tabular}

* Different letters indicate significant differences at 5\% (Duncan's test).

There are 3 possible methods of breaking the dormancy of beechnuts: before, after or during storage. A dormancybreaking treatment applied before storage is the only one providing a constant supply of dried, non-dormant beechnuts that are able to germinate without any pretreatment (Muller and Bonnet-Masimbert, 1985).

The optimum conditions of the treatment are: hydration of the seeds to $30 \%$ moisture content (fresh weight basis) and maintaining the seeds at $3^{\circ} \mathrm{C}$ for a period 2 wk longer than the classical cold stratification method. This precise $30 \% \mathrm{MC}$ of the seed is enough for the dormancy breaking process to function. However, it does not allow the seeds to germinate and, after pretreatment, seeds can be dried and stored for several years.

Non-dormant beechnuts have been tested in the laboratory and in the nursery. Table I shows the results for pretreatment of seeds without medium, either before or after storage, in comparison to the classi- cal stratification procedure. Pretreatment before storage produced significantly better results. We are now storing more than 30 non-dormant seed lots, some of them for nearly $6 \mathrm{yr}$.

Of special interest are the results for nursery bed emergence, probably indicating a good adaptation of the treated seeds to irregular environmental conditions in a nursery (Muller and BonnetMasimbert, 1989).

\section{Fraxinus excelsior}

Samaras of Fraxinus excelsior present a physiological dormancy combined with an underdeveloped embryo. For breaking the dormancy of this species, it was necessary to apply a warm + cold phase treatment for 32 wk.

As for beechnuts, we have different ways to combine the dormancy breaking treatment after collection and storage (Table II). The dormancy can be removed

Table II. Germination percentages for Fraxinus excelsior comparing before and after storage dormancy-breaking treatments.

\begin{tabular}{llll}
\hline Lot & $\begin{array}{l}\text { Warm + cold } \\
\text { before storage }\end{array}$ & $\begin{array}{l}\text { Warm before storage } \\
\text { cold after }\end{array}$ & $\begin{array}{l}\text { Warm + cold } \\
\text { after storage }\end{array}$ \\
\hline A & 89 & 93 & 98 \\
B & 69 & 75 & 71 \\
\hline
\end{tabular}


before (i.e., after collection), after or during storage. It is now possible to eliminate prestorage dormancy after collection, either by affecting underdevelopment (i.e., warm phase) or underdevelopment + dormancy (i.e., warm + cold phase).

\section{Prunus avium}

For this species, an important dormancy problem also exists, which results in poor control of germination, a huge waste of seeds and poor yields in the nursery, rarely exceeding 15-20\%. The deep dormancy which affects the seeds can be removed with an alternate warm and cold treatment applied with or without medium.

For the last few years, we have tried to determine the optimal treatment convenient for all seed lots. Presently, the best one is 3 warm and 3 cold phase treatments. Although this protocol yields a complete and uniform germination, it is very long and often needs $20-24$ wk before the beginning of the germination. For this reason, we were interested in applying the new methodology before storage. Good results have been obtained after $1 \mathrm{yr}$ of storage with non-dormant stones.

\section{Conclusion}

Today, the ability to supply, at any time, non-dormant seeds, ready to germinate, after storage periods of up to $5 \mathrm{yr}$ without any pretreatment represents real progress in the technology of forestry seed handling. Especially well-adapted to the normal heterogeneity of forest seeds, this new methodology has been tested on a large scale with Fagus silvatica in the seed plant of the French Office National des Forêts with high hopes of yielding substantial improvement in production of beech seedlings. It is presently the best method for the nurseryman who can now choose the date of sowing in relationship to good climatic conditions, whereas formerly the date was determined by the beginning of the pretreatment (hence $1-8$ mo earlier).

Moreover, with reduced failure at the time of germination, a decrease in waste of forestry seecls and probably in waste of important genotypes may be a reasonable expectation.

\section{References}

Muller C. \& Bonnet-Masimbert M. (1985) Levée de dormance des faines avant leur conservation: résultats préliminaires. Ann. Sci. For. 42 , 385-396

Muller C. \& Bonnet-Masimbert M. (1989) Breaking dormancy before storage: an improvement to processing of beechnuts (Fagus silvatica). Seed Sci. Techno!. (in press)

Suszka B. (1975) Cold storage of after-ripened beech (Fagus silvatica) seeds. Arbor. Kornickie 299-315 